\title{
FOREST CONVERSION TO OIL PALM COMPRESSES FOOD CHAIN LENGTH IN TROPICAL STREAMS
}

Clare L. Wilkinson, Kenny W. J. Chua (D), Roswitha Fiala, Jia Huan Liew, Victoria Kemp, Arman Hadi Fikri, Robert M. Ewers, Pavel Kratina (D), and Darren C. J. Yeo

\section{Study Description}

The study took place at the Stability of Altered Forest Ecosystems project, in the southeast of Sabah, Malaysia, which was set up to understand the impacts of deforestation and conversion of rainforest to oil palm plantations on biodiversity, ecosystem functioning and processing, at multiple spatial scales. This project used stable isotope analysis to explore how freshwater food webs in small streams were impacted across the land use gradient, including streams in primary forest, logged forest, and oil palm plantations.

Wilkinson, C. L., K. W. J. Chua, R. Fiala, J. H. Liew, V. Kemp, A. Hadi Fikri, R. M. Ewers, P. Kratina, and D. C. J. Yeo. 2020. Forest Conversion to Oil Palm Compresses Food Chain Length in Tropical Streams. Bull Ecol Soc Am 102(2):e01826. https://doi.org/10.1002/bes2.1826 


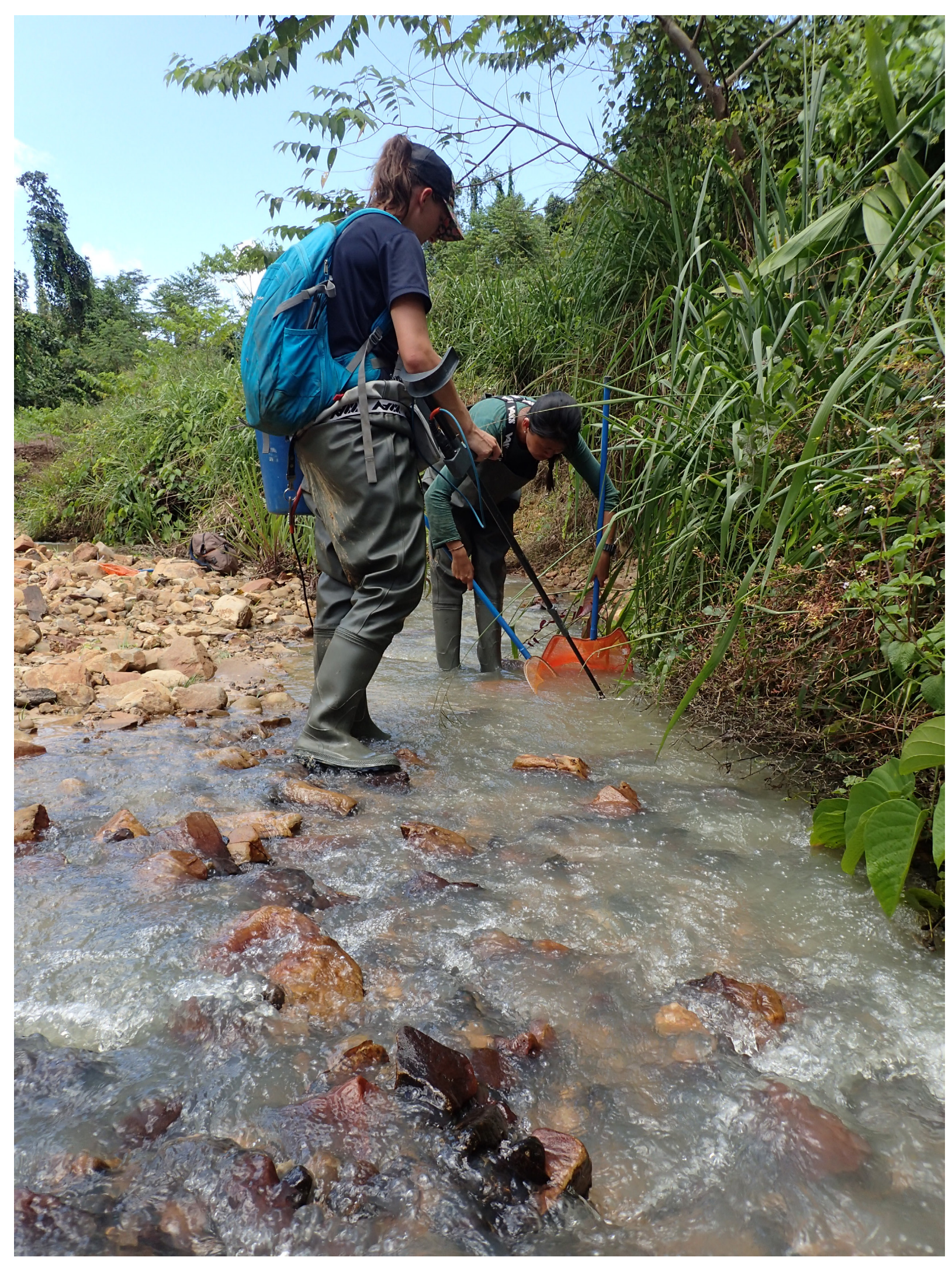

Photo I: Freshwater fieldwork at the SAFE project in Sabah, Malaysia. Researchers sampling a stream using electrofishing equipment to catch fish. Photo credit: Tan Heok Hui. 


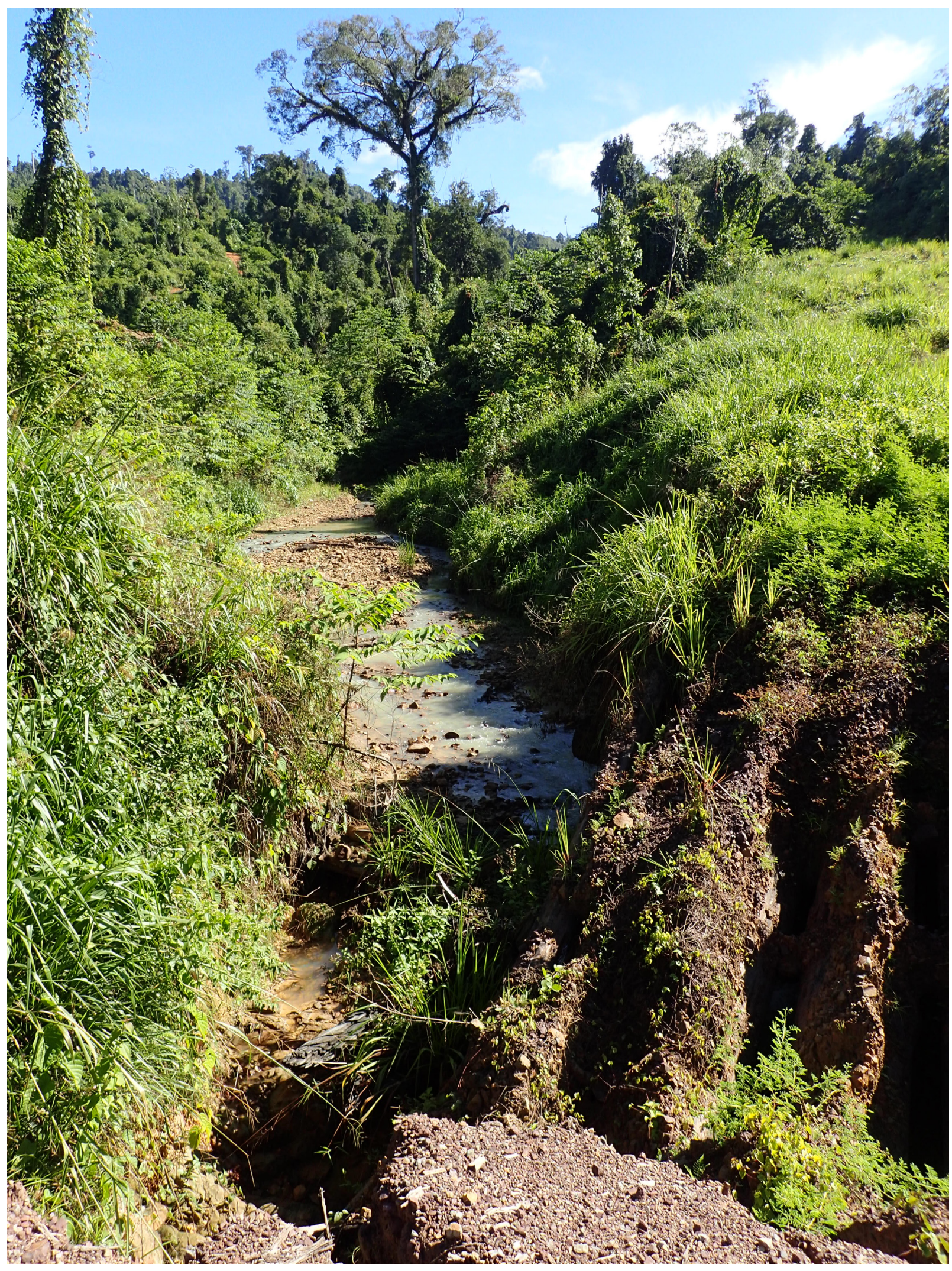

Photo 2: Freshwater fieldwork at the SAFE project in Sabah, Malaysia-A logged forest stream to sample. Photo credit: Tan Heok Hui. 


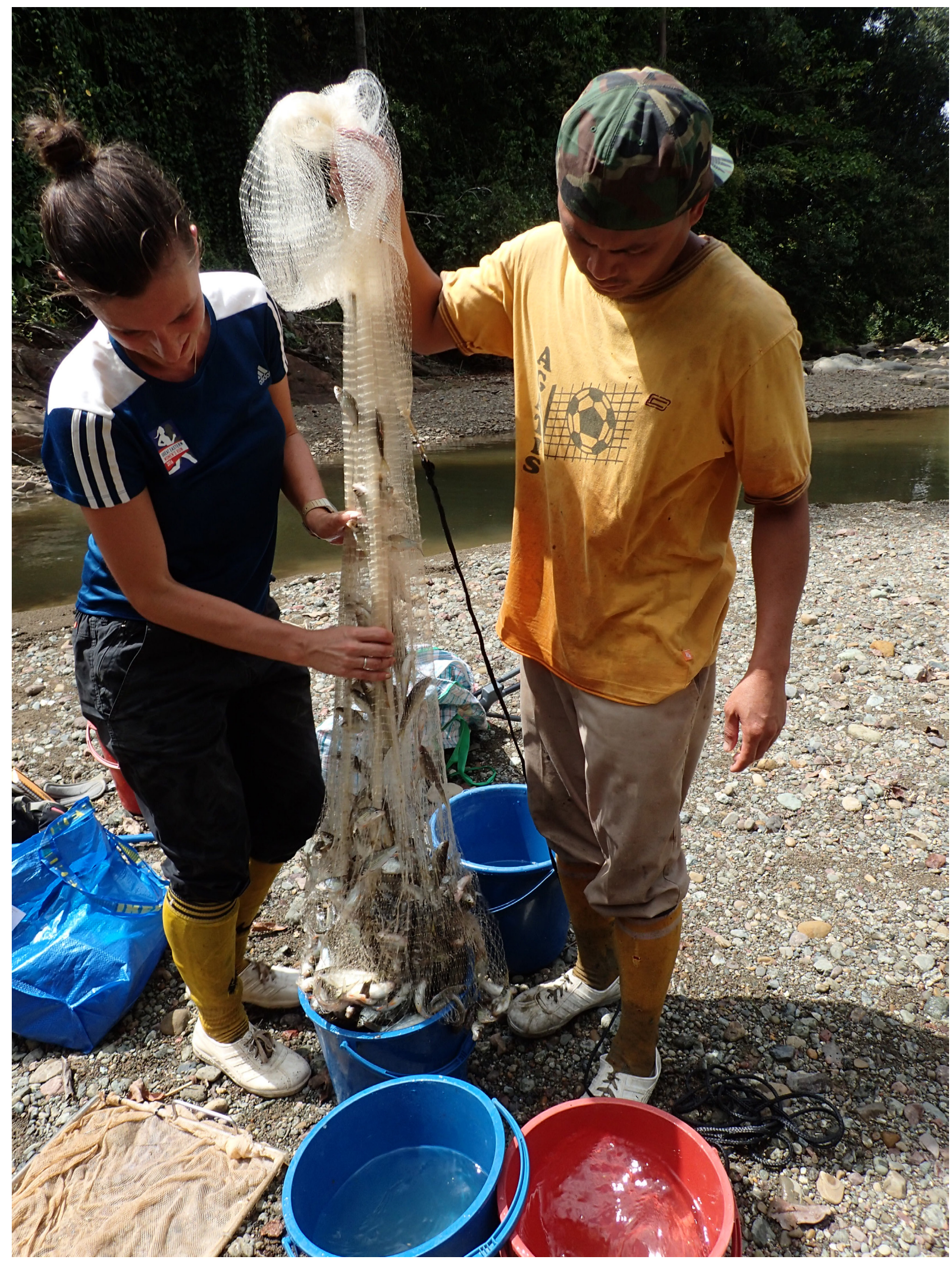

Photo 3: Freshwater fieldwork at the SAFE project in Sabah, Malaysia. Researchers removing fish from a cast net during sampling at a logged forest stream. Photo credit: Tan Heok Hui. 
These photographs illustrate the article "Forest conversion to oil palm compresses food chain length in tropical streams" by Clare L. Wilkinson, Kenny W J Chua, Roswitha Fiala, Jia Huan Liew, Victoria Kemp, Arman Hadi Fikri, Robert M Ewers, Pavel Kratina, and Darren C J Yeo published in Ecology. https://doi.org/10.1002/ecy.3199. 